\title{
Habitat Quality Analysis of Natura 2000 Riparian Forests
}

\author{
Barbara RIEDLER, Thomas STRASSER, Lena PERNKOPF, \\ Dirk TIEDE and Stefan LANG \\ Department of Geoinformatics - Z_GIS, University of Salzburg/Austria ·barbara.riedler@sbg.ac.at
}

This contribution was double-blind reviewed as extended abstract.

\section{Introduction}

Riparian forests are sensitive habitats with a rich biodiversity and an important function as corridors for movement of wildlife. In Europe, many of these precious habitats are protected sites within the Natura 2000 network, where monitoring results have to be reported every six years. Satellite imagery provides key benefits for monitoring nature protection areas where political borders, rough terrain and large and/or complex monitoring areas handicap a harmonized assessment (VANDEN BORRE et al. 2011). NAGENDRA et al. (in press) name four critical aspects of assessment: changes in habitat extent and landscape structure, habitat degradation, alteration in biodiversity and tracking of pressures and threats within and outside protected areas. As silviculture inside Natura 2000 sites can influence these aspects, a targeted monitoring is needed. For this purpose, an Earth observation-based workflow has been developed within the MS.MONINA project (http://www.ms-monina.eu) to monitor riparian forests in the Natura 2000 site Salzachauen. It includes (1) a habitat delineation based on visual interpretation and semi-automated object-based image analysis and (2) an assessment of habitat quality using structural indicators (cf. STRASSER et al. in review). In this paper, we focus on the second part of this workflow. We used landscape metrics to assess the overall habitat quality of the entire area and differentiated between three subregions with a different degree of silvicultural intensity to reveal potential influence of forest management on the habitat quality.

\section{Method}

The Natura 2000 site Salzachauen, Austria is located along the regulated river Salzach in a densely populated area of the alpine foreland at the Austrian-German border. Dominating Natura 2000 habitat types are alluvial forest $(91 \mathrm{E} 0 *)$ and riparian mixed forest (91F0) characterized by a high abundance of endangered species.

Analyses were done on a visual habitat delineation derived from a very high resolution WorldView-2 satellite image (acquired in June 2012 with 0.5 ground sample distance). The EUNIS-3 classification scheme (DAVIES et al. 2004) served as a basis for the habitat delineation. In the case of riparian forests it can be used complementary to the Natura 2000 classification scheme and has the advantage of providing a hierarchical structure. For further analysis the delineated EUNIS-3 patches were aggregated to three categories: 
riparian forest (G1.1, G1.2), managed forest (G1.C, G3.F, G4.F, G5.1, G5.2, G5.4, G5.5) and recently felled areas \& afforestation (G5.6, G5.8). To assess the impact of silvicultural practices on the Natura 2000 site, the area was divided into three parts with different intensities in usage: (I) no/little, (II) medium and (III) intense silvicultural use (Fig. 1a).

Patch density, mean patch size and patch size coefficient of variation were calculated to detect structural heterogeneity (LANG et al. 2008, AGUIAR et al. 2011). Edge density was used to reveal structural richness, which is, under certain conditions, assumed to characterize habitats of high quality (LANG et al. 2008). Prior to the calculation we assured that only those edges were considered that have a positive effect on structural diversity and excluded forest roads. Edge density calculation was conducted with a self-programmed Python geoprocessing script in ArcGIS. Shape index (FORMAN \& GODRON 1986) was computed on single patch level using V-LATE (Vector-based Landscape Analysis Tools Extension for ArcGIS, LANG \& TIEDE 2003). AGUIAR et al. (2011) showed that shape index can be used as a standardised indicator for describing form complexity of riparian forest patches and thus can reflect natural habitat conditions (STRASSER et al. 2012). To validate differences, statistical analyses (Kruskal-Wallis (KW) and Mann-Whitney U (MWU) as non-parametric tests for independent samples) were performed.

\section{Results}

Areas with intense silvicultural use (III) showed on average a higher patch density and lower mean patch size, both indicating high heterogeneity (Tab. 1). In general, this is considered a positive indication for habitat quality. However, in this case low heterogeneity
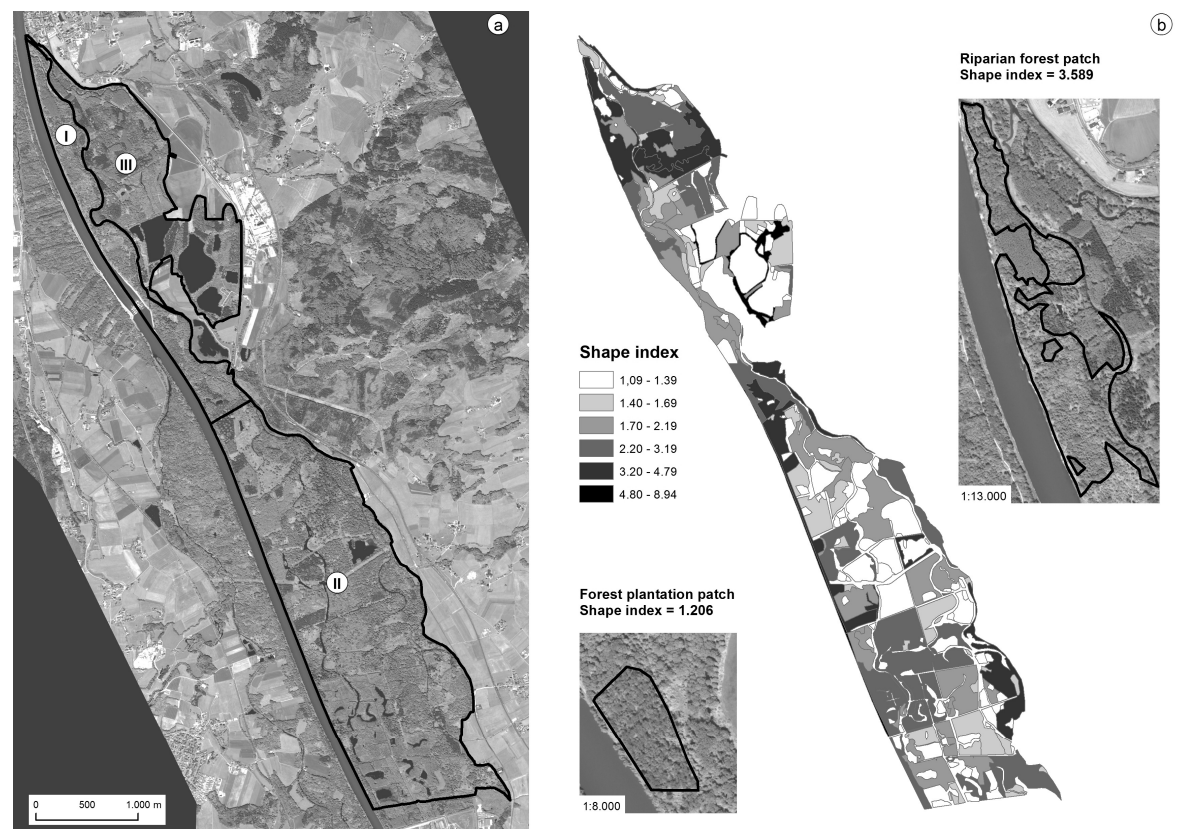

Fig. 1: (a) FFH site, divided in subregions with similar predominating silvicultural use;

(b) shape index values 
indicates a better habitat quality, since heterogeneity is mainly caused by forest plantations (Fig. 1a). This is confirmed by the lower values of the patch size coefficient of variation in areas with little/no silvicultural use (I), indicating similar patch sizes and thus little heterogeneity (Tab. 1). In line with the assumption that natural forests are structurally more complex, high edge density values were primarily found in areas with no/little silvicultural use, which also have the highest proportion of natural riparian forest habitats (Tab. 1).

Table 1: Structural indicators

\begin{tabular}{|c|c|c|c|c|c|c|}
\hline \multirow{2}{*}{$\begin{array}{l}\text { SILVI- } \\
\text { CULTURAL } \\
\text { USE }\end{array}$} & \multicolumn{3}{|c|}{ HETEROGENEITY } & \multirow{2}{*}{$\begin{array}{c}\text { FORM } \\
\begin{array}{c}\text { Mean shape } \\
\text { index }\end{array}\end{array}$} & \multirow{2}{*}{$\begin{array}{l}\text { STRUCTURE } \\
\underset{(\mathrm{m} / \mathrm{ha})}{\text { Edge density }}\end{array}$} & \multirow{2}{*}{$\begin{array}{l}\text { DIVERSITY } \\
\text { Proportion of } \\
\text { riparian forest } \\
\text { habitats (\%) }\end{array}$} \\
\hline & $\begin{array}{c}\text { Patch } \\
\text { density }\end{array}$ & $\begin{array}{c}\text { Mean patch } \\
\text { size (ha) }\end{array}$ & $\begin{array}{c}\text { Patch size } \\
\text { coefficient of } \\
\text { variation }(\%)\end{array}$ & & & \\
\hline no/little & 0.3169 & 3.1557 & 134.79 & 1.9678 & 232.52 & 55.89 \\
\hline II medium & 0.3401 & 2.6856 & 181.75 & 1.7155 & 173.54 & 50.58 \\
\hline III intense & 0.4964 & 2.0146 & 199.20 & 1.7037 & 167.85 & 29.34 \\
\hline
\end{tabular}

High shape index values are primarily found in areas with meandering rivulets indicating optimal riparian forest conditions, whereas low shape index values reflect small compact forms, which are in most cases the result of anthropogenic forest management (Fig.1b). Shape index values vary significantly with different intensity of silvicultural use (KW, $\mathrm{p}<0.009)$ and habitat status categories $(\mathrm{KW}, \mathrm{p}<0.000)$. Following the assumption that natural forests and thus also areas with a high proportion of riparian forest habitats are characterized by more complex patch forms, the shape index proved to be a suitable measure to differentiate riparian forest from other habitat status categories (MWU, $\mathrm{p}<0.000$; Fig. 2a) and areas with not/little silvicultural use from areas with more intense usage (I-II: MWU, p<0.003, I-III: MWU, p<0.006; Fig. 2b).

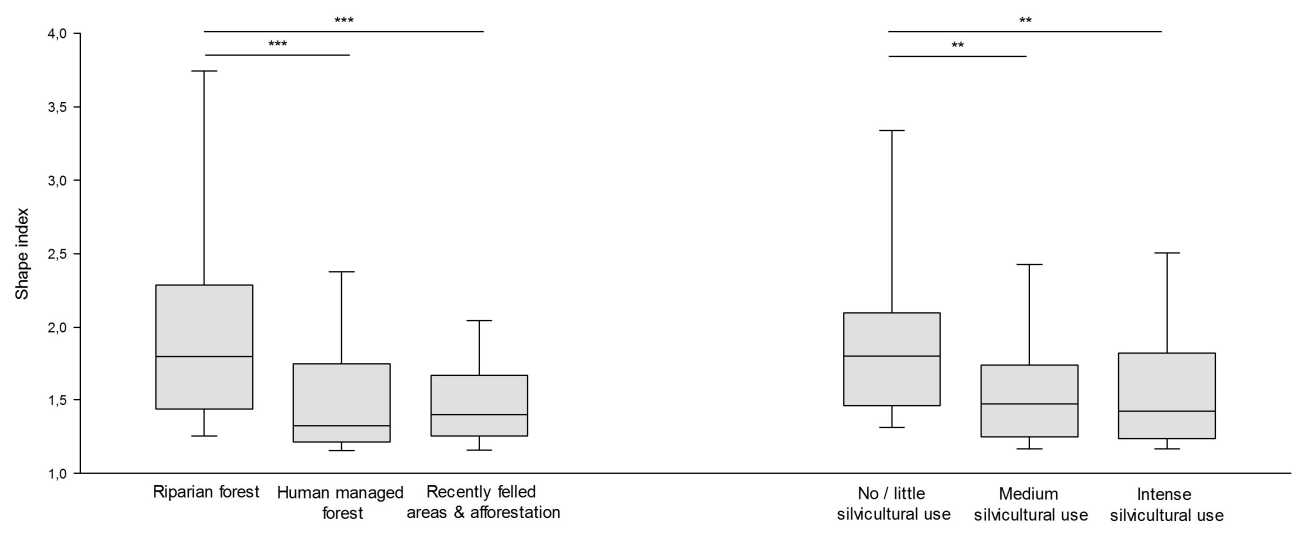

Fig. 2: Statistical differences of shape index values between (a) habitat status categories and (b) subregions with different intensity of silvicultural use. Significance levels: $* * \mathrm{p}<0.01 * * * \mathrm{p}<0.001$. 


\section{Conclusion and Outlook}

This study showed that the selected landscape metrics are suitable to detect differences in habitat quality. Shape index as a form indicator can be used to distinguish between habitat status categories but also help discern areas with different intensity of silvicultural use. For the latter, a combination of indicators is essential to provide a meaningful interpretation. High values of structure and form parameters in combination with low values of heterogeneity parameters thereby indicate high habitat quality.

In line with the MS.MONINA workflow for monitoring riparian forests, habitat quality analysis will also be performed based on the results of the semi-automated habitat classification. Time series analyses are planned for the future to evaluate changes in landscape pattern and habitat quality as well as to assess the effectiveness of management strategies.

\section{References}

Aguiar, F. C., Fernandes, M. R. \& Gerreira, M. T. (2011), Riparian vegetation metrics as tools for guiding ecological restoration in riverscapes. Knowledge and Management of Aquatic Ecosystems, 204, 21.

DAvies, C. E., Moss, D. \& HiLl, M.O. (2004), EUNIS Habitat Classification Revised 2004. http://eunis.eea.europa.eu/upload/EUNIS_2004_report.pdf.

FORMAN, R. T. T. \& GODRON, M. (1986), Landscape ecology. New York, Wiley.

LANG, S. \& TIEDE, D. (2003), vLATE Extension für ArcGIS - vektorbasiertes Tool zur quantitativen Landschaftsstrukturanalyse, ESRI $18^{\text {th }}$ User Conference, Innsbruck.

LANG, S., WAlZ, U., Klug, H., BlaschKe, T. \& SyRBE, R.-U. (2008), Landscape metrics a toolbox for assessing past, present and future landscape structures. In: Geoinformation Technology for Geo-Cultural Landscape Analysis: European Perspectives, KREK, A., EVELPIDOU, N. \& BENDER, O. (Eds.). Leiden, CRC Press, 207-234.

Nagendra, H., Lucas, R., Honrado, J. P., Jongman, R. H. G., TARAntino, C., Adamo, M., MAIROTA, P. (in press), Remote sensing for conservation monitoring: Assessing protected areas, habitat extent, habitat condition, species diversity, and threats, Ecological Indicators.

Strasser, T., Lang, S., Pernkopf, L. \& Paccagnel, K. (2012), Object-based class modeling for assessing habitat quality in riparian forests. In: Proceedings of GEOBIA 2012, 555-560.

Strasser, T., Lang, S., Riedler, B., Pernkopf, L. \& Paccagnel, K. (in review), Multiscale Object Features for Habitat Quality Monitoring in Riparian Forests. Geoscience and Remote Sensing Letters.

Vanden Borre, J., Haest, B., Lang, S., Spanhove, T., Förster, M. \& N. Sifakis (2011), Towards a wider uptake of remote sensing in Natura 2000 monitoring: Streamlining remote sensing products with users' needs and expectations, Proceedings of the 2nd International Conference on Space Technology (ICST), Athens. 